plicand as in Table 8.1 ? Confusion of this kind emphasizes the need for universal acceptance of a rational means of expressing units.

The book is well written, clearly printed and marred by few errors. Much of the literature on pulse radiolysis up to the end of 1967 , a period of very rapid development for the technique, is reviewed and for this reason alone the book must be worth a place on the shelves of both radiation chemists and general kineticists.

G. Arthur Salmon

\section{SPACE IN TIME}

\section{Concepts of Space}

The History of Theories of Space in Physics. By Max Jammer. Second edition. Pp. xv+221. (Harvard University Press: Cambridge, Massachusetts; Oxford University Press: London, September 1969.) 52s.

The first edition of this book, published in 1954, was widely welcomed as an enthralling account of the evolution of the concept of space in physics. In the first of his five chapters, the author discussed the ideas of antiquity, notably the rival conecpts of tho plenum and the void. In chapters four and five he gave a masterly account of the history of the idea of space since the time of Newton, but the unique feature of Jammer's book was the fascinating discussion in chapters two and three of the Jewish and mediaeval Christian ideas that culminated in the Newtonian concept of absolute space. The mythical association of the ideas of God and space was shown to have had a long history and to have played an important part in the evolution of physies. From prehistoric times light was a symbol of supernatural forces; therefore the association of God and space led to the identification of space and light. This identification exerted an important influence on Grosseteste (at Oxford) and others in the thirteenth century, who believed that the key to knowledge of the universe lay in the study of geometrical optics. This idea was a major stimulus to the revival of mathematical physics that led, after some delay, to the scientific revolution in the seventeenth century.

Careful collation of the present and the first editions reveals that the only significant difference is the addition of just over twenty pages at the end of the fifth chapter to cover the following topics that have been written about in the past fifteen years-Mach's principle, parity, the dimensionality of physical space, the controversy concerning the respective roles of empirical and conventional factors in physical geometry, and rocent investigations on the microstructure of space. All these are well summarized and up to the high standard of the rest of the book. It is a pity, however, that the author doos not mention one of the most important discoveries in recent years concerning space in cosmological models, a discovery that was obvious once someone pointed it out: namoly, that the topology of space is independent of the metric, so that, for example, the metric of the Einstein universe does not by itself necessarily imply that the spatial extent of this universe must be finite, as had previously been assumed.

\section{G. J. WHITROW}

\section{SPECIAL FUNCTIONS}

\section{Funetions of Mathematical Physics}

By B. Spain and M. G. Smith. (The New University Mathematics Series.) Pp. xi +208 . (Van Nostrand Reinhold; London and New York, January 1970.) 80s boards; $40 s$ paper.

THE book follows the traditional approach to the special functions of mathematical physics. The first half of the book consists of four chapters which give a concise account of the solution of linear ordinary difforential equations by series and by means of contour integrals, Sturm-Liouville theory and the theory of asymptotic expansions. The second half develops the properties of each special function in turn, starting from its definition. There is a good index.

There are many helpful illustrative examples and many exercises. In one or two places the argument is unclear. For example, in the solution by contour integral of the differential equation with constant coefficients, the contour is suddenly and tacitly assumed to be closed, and the arbitrary constants appear abruptly without clear intro. duction.

The book stays unexcitingly close to its objective. The physical relevance of the functions is mentioned only in the two appondices which summarize the equations obtained by separating the Helmholtz and Schrödinger equations in various coordinates. The connexion between groups of transformations and special functions is not mentioned. Nor is there montion of functional analysis. The treatment of the completeness of the sets of orthogonal functions suffers in consequence. But as a result of this concentration of interest, the book obtains rapidly and with explanation all the properties of the special functions which one is likely to need in physics and engineering.

\section{F. J. BLOORE}

\section{LIGAND FIELD THEORY}

\section{Basic Principles of Ligand Field Theory}

By H. L. Schlafer and G. Gliemann. Translated by D. F. Ilten. Pp. $x v+535$. (Wiley (Interscience): London and New York, 1969.) $160 s$.

Texts devoted to various aspects of crystal and ligand field theory continue to proliferate, and this volume, although claiming to "offer the chemist an easily readable introduction to the subject", is clearly directed to those already familiar with much of the basio theory and to those whose research interests lie in this area.

The book is divided into two principal sections, the first and shorter section being an essentially qualitative discussion of the origins of the crystal field model and its application in interpreting the properties of transition metal complexes, while the second section contains five chapters, four of which are devoted to a detailed mathematical development of the subject. It is in this second section that the principal value of the book lies, and in view of its price it would be an expensive purchase for those whose interest in the subject does not reach this level.

The major concepts are introduced in the first chapter, which is largoly devoted to an account of the spectroscopic properties of coordination compounds and includes a fairly detailed discussion of such topics as the weak and strong field models, term diagrams, charge transfer spectra, intensities of absorption bands, and the like. The second chapter gives a fairly elementary account of magnetochemistry, and it is unfortunate that the authors introduce alternative labelling for the $d$ orbitals here, rather than using the Mulliken notation introduced in the first chapter. The next three chapters in this section, devoted respectively to ligand field stabilization energies, the JahnTeller theorem and its consequences and a very brief discussion of the kinetic stability of coordination compounds, all secm to be out of place in a book of this kind; and the material of the last chapter, being a résumé of the experimental cvidence for the ligand field rather than the crystal field model, could have been successfully, and more profitably, integrated into chapter ono. (A similar comment could be made concerning much of the material in the chapter devoted to the Jahn-Teller effect.)

The first two chapters of the second section aro devoted respectively to a treatment of the relevant theory of multielectron free atoms and ions and to the theory of 